\title{
Socioeducação e juventude: reflexões sobre a educação de adolescentes e jovens para a vida em liberdade
}

\author{
Social education and youth: reflections on the education of adolescents and young people \\ for life in freedom
}

Silmara Carneiro e Silva*

\begin{abstract}
Resumo:
O presente artigo tem por objetivo refletir sobre a juventude na sua relação com o fenômeno da violência e o cometimento de atos infracionais, apontando a política pública de socioeducação como uma alternativa de educação de adolescentes e jovens para a vida em liberdade. A metodologia utilizada foi a pesquisa bibliográfica, com base em autores da área de ciências sociais aplicadas. A socioeducação é vista como uma política pública que tem por objetivo construir, junto dos adolescentes e jovens, novos e apropriados conceitos de vida, buscando o fortalecimento dos princípios éticos da vida social. Para tanto, no presente artigo parte-se do pressuposto que a socioeducação é uma política que tem como proposta a educação para a vida em liberdade, verificando-se com a discussão teórica realizada que, para a referida política se efetivar como tal, faz-se necessária a construção de meios para a efetivação de ações que se configurem para além do sentido da responsabilização do adolescente pelo ato infracional, pois sua natureza pedagógica e social deve ser o pressuposto básico de todas as práticas socioeducativas. Enquanto política pública deve se efetivar em conjunto com a família, com a comunidade e com a sociedade em geral, mas sem desresponsabilizar o Estado brasileiro pela condução e direção da referida política no âmbito da sociedade contemporânea, uma vez que as condições materiais e concretas para a construção das possibilidades de liberdade devem ser providas ao adolescente, como condição para seu desenvolvimento pessoal e social enquanto sujeito de direitos.
\end{abstract}

Palavras-chave: Socioeducação. Juventude. Liberdade.

\begin{abstract}
:
This article aims to reflect on youth in relation to the phenomenon of violence and committing illegal acts, pointing out the public policy of social education as an alternative education for adolescents and young people to live in freedom. The methodology used was a literature search based on authors in the field of applied social sciences. The social education is seen as a public policy that aims to build, among adolescents and youth, and appropriate new concepts of life, seeking to
\end{abstract}

\footnotetext{
* Assistente social do Centro de Socioeducação de Ponta Grossa da Secretaria de Estado da Família e Desenvolvimento Social do Estado do Paraná. Graduada em Serviço Social pela Universidade Estadual de Ponta Grossa - UEPG, Especialista em Administração Estratégica de Pessoas pela Faculdade Pe. João Bagozzi, Especialista em Mídia, Política e Atores Sociais pela UEPG, Mestre em Ciências Sociais Aplicadas pela UEPG e Doutoranda em Serviço Social e Política Social pela Universidade Estadual de Londrina - UEL. E-mail: verdesilmara@yahoo.com.br.
} 
strengthen the ethical principles of social life. To do so, in this paper starts from the premise that education is a social policy that has the purpose of education for life in freedom, checking in with the theoretical discussion held that the policy to be effective as such, becomes required the construction of means for the accomplishment of actions that are configured to the sense of accountability for adolescent misdemeanors, for their educational and social nature should be the basic assumption of all social and educational practices. While public policy should become effective in conjunction with the family, community and society in general, but the Brazilian State harmless without the conduct and direction of policy in the context of contemporary society, since the material and concrete the construction of the possibilities of freedom should be provided to adolescents as a condition for their personal development and social rights as a subject.

Keywords: Social education. Youth. Freedom.

\section{Introdução}

Partimos do entendimento de que na contemporaneidade a situação pessoal, social, cultural e política de adolescentes e jovens em conflito com a lei se inscrevem em um contexto de fragilidade do pacto societário, cujas consequências têm-lhes atingido sumariamente em seu desenvolvimento histórico. A privação dos direitos assegurados a essa parcela da população torna-se uma dos condicionantes da sua fragilidade, frente às obrigações atribuidas ao indivíduo em um Estado Democrático de Direito. O não acesso à boas condições de saúde, a uma educação de qualidade, aos mínimos necessários para a sobrevivência, à moradia adequada, a equipamentos comunitários de lazer, esportes e cultura, entre outros espaços de socialização saudáveis e de desenvolvimento humanos torna-se fator determinante para a fragilização dos sujeitos em seu ambiente familiar, comunitário e social.

As diversas expressões da violência, os conflitos familiares e comunitários, a desigualdade social, a exclusão e a ausência de garantias e políticas públicas transformam determinados adolescentes e jovens em sujeitos vulneráveis à criminalidade. A prática de atos infracionais, nesse contexto, constitui-se como um dos resultados de toda essa dinâmica de privações e violações, na qual adolescentes e jovens protagonizam ações que corroboram para o ciclo de violência vividos. A fragilização de adolescentes e jovens que não alcançam condições mínimas para seu desenvolvimento pessoal e social frente aos desafios da vida em liberdade é, portanto, um dos fatores que os condicionam à prática de atos infracionais e os colocam na condição de sujeitos em conflito com a lei. 
Enquanto resposta do Estado à demanda de adolescentes e jovens em conflito com a lei no Brasil, a política de socioeducação se confronta com uma realidade na qual o trabalho com os adolescentes e jovens em cumprimento de medida socioeducativa demanda o aprendizado de questões elementares para a construção de um padrão de convivência ético no âmbito da vida em liberdade. A contrução de ações de inclusão e acesso desta parcela da população a bens e serviços básicos para sua sobrevivência num patamar mínimo de dignidade humana e o trabalho educativo realizado no cotidiano das instituições de socioeducação vai delineando, cada vez mais, a socioeducação como uma política de educação para a vida em liberdade.

Transportando os pressupostos acima anunciados ao conjunto de mediações realizadas neste artigo, tem-se por objetivo tratar das questões da juventude na sua relação com o fenômeno da violência e o cometimento de atos infracionais, refletindo sobre a política pública de socioeducação, enquanto uma proposta de educação para a vida em liberdade.

\section{Juventude, violência e o cometimento de atos infracionais no Brasil}

A violência está inscrita no âmago das relações sociais, sendo parte constitutiva do modo como o homem se relaciona com os outros homens e com a natureza. Esta se reproduz no âmbito da sociedade como expressão da manipulação humana em meio aos padrões de sociabilidade construídos historicamente. "A violência é, pois manifestação do poder, expressão de como as relações sociais estão aqui organizadas [...]. É exploração, opressão e dominação, mas não é somente força pura, é também ideologia e sutileza" (SALES, 2007, p. 59).

Desde a antiguidade até a sociedade moderna, a violência tem sido utilizada como um meio e/ou instrumento para satisfação das necessidades e/ou interesses humanos, e desde então vem acumulando formas de se relacionar que culminam com a utilização de diferentes formas de violência como subterfúgio ao alcance de um estado de sociabilidade. Nogueira (2001) aponta que no mundo moderno a violência passou a ser ação exclusiva do Estado, pois "[...] uma comunidade humana que, dentro dos limites de determinado território - [...] reivindica o monopólio do uso legítimo da violência física." (WEBER, 2007, p. 60). 
Indivíduos, grupos e classes sociais possuem o dever de conviver no espaço público, seguindo aos padrões de civilidade oficiais vigentes. Toda e qualquer ação contrária à moralidade e à ética é, neste caso, considerada uma conduta desviante e passível de repressão estatal.

Num contexto de reprodução de relações violentas, perpassadas pelas consequências da desigualdade social, dos processos de exclusão, de ausência de políticas públicas, precariedade nas relações familiares e comunitárias, da criminalização da pobreza e da supremacia do tráfico de armas e drogas, como umas das mais severas expressões do crime organizado, a sociedade torna-se alvo das mais variadas formas de violência.

Inseridos neste contexto, a sociedade contemporânea tem acompanhado, cotidianamente pela mídia, na produção acadêmica e nos debates públicos, sobre a juventude, que esta tem sido cada vez mais alvo privilegiado de ações violentas, nas quais tanto é vítima como agressora. A repressão e as ações pedagógicas e sociais em torno do enfrentamento da questão da violência juvenil são desafios importantes no cenário atual tanto para o Estado quanto para a sociedade em geral.

A fragilização das relações sociais vai se desenvolvendo como consequência de uma sociabilidade inscrita em um contexto de inseguranças. Inseridos nesse processo histórico e social, adolescentes e jovens tornam-se os alvos mais expostos às determinações do fenômeno da violência.

Visando a proteção especial desta parcela da população, o Estatuto da Criança e do Adolescente, Lei 8.069/90, aponta que crianças e adolescentes estão em uma fase na qual possuem "uma condição peculiar de desenvolvimento". Nesta fase da vida, o sujeito está construindo sua identidade, tornando-se mais expostos às diferentes influências, motivações e ou orientações, seja da família, de amigos e outros grupos pertencentes ao seu ambiente de sociabilidade.

A vulnerabilidade e o risco imbutidos em um padrão de sociabilidade sem condições mínimas de sobrevivência, de imposição de regras e limites necessários à convivência social e de condições dignas econômicas, sociais e de afetividade e proteção expoem com maior intensidade fatores agregados ao fenômeno da violência na contemporaneidade. Assim, crianças, adolescentes e jovens sem condições de proteção 
integral passam a uma posição de maior exposição a práticas violentas, sendo a vida infracional um aspecto desta complexa realidade. O fator econômico não é motivo suficiente para a explicação da violência, mas sim da forma violenta como a sociedade contemporânea se estrutura. Os níveis de desigualdade social, a pobreza e as diversas questões que implicam uma situação de vulnerabilidade e risco ao ser humano são expressões da violenta forma como a humanidade se organiza socialmente.

Diversas questões, portanto, corroboram para que a população juvenil esteja potencialmente exposta aos riscos inerentes a um padrão de sociabilidade violento. Adolescentes e jovens, inseridos em contextos violentos, tornam-se mais diretamente expostos à incorporação de uma sociabilidade iminentemente violenta. O cometimento de atos infracionais torna-se parte desta maneira de viver atrelada a uma vida plenamente insegura, sem projetos e sem perspectiva e sem proteção.

Conforme Cordeiro e Volpi (2010, p. 54):

\begin{abstract}
Seria simples estabelecer uma relação de causa e efetio entre a pobreza sofrida cotidianamente por esses adolescentes e os atos infracionais por eles cometidos. É falso, porém, de um ponto de vista sociológico, que a miséria produza violância, ja que a relação entre as duas não é biunívoca. Hoje trabalha-se com a idéia de que a violência é provocada por vários fatores que, dependendo do contexto, desempenham pesos diferentes.
\end{abstract}

O ingresso em práticas de atos infracionais torna-se um elemento inserido no âmbito dos demais elementos que compõem o cenário de vulnerabilidade, de falta de oportunidades e de exposição à violência.

Questões como problemas familiares, conflitos interpessoais, violência doméstica, abandono familiar; problemas de saúde física e mental, geralmente atrelados ao uso abusivo de drogas e ou por questões psicológicas e psíquicas; déficit de aprendizagem e evasão escolar; conflitos comunitários, interpessoais; situações de rua; falta e ou insuficiência de renda; envolvimento com grupos criminosos; gangues e organizações para o tráfico de drogas fazem parte das experiências de vida de adolescentes e jovens em conflito com a lei, e cada uma das referidas questões contribuem particularmente para os rumos da sociabilidade de cada adolescente, tornando-se fatores atrelados ao fenômeno da juventude na sua interface aos cometimentos de atos infracionais. Relacionados a padrões de sociabilidade violentos estão imbricados fenômenos típicos 
como ameaças, agressões físicas e ou homicídios relacionados a cobranças de dívidas e ou por não observação de códigos morais próprios.

Fraga (2010, p. 86), retratando o fenômeno da violência no Brasil, aponta que a “[...] capacidade de vitimizar pessoas cada vez mais jovens dos estratos populares, de forma tão banalizada e invisível, apresentou-se como um dos aspectos mais relevantes da violência da criminalidade dos anos 1990."

Assim, inserem em um ciclo de violência que embora

[...] seja estruturalmente produzida pelas elites, como um dos mecanismos que sustentam e fazem a política e a economia, não constitui seu patrimônio exclusivo. Reproduzida pelos mais diversos estratos sociais, tende, porém, a ser associada de maneira reducionista e invertida, pelo senso comum, aos pobres e miseráveis, vistos como "classes perigosas", e de onde provém os "maus elementos" (SALES, 2007, p. 59).

Ao longo deste processo de discriminação, exclusão e marginalização, a maioria dos adolescentes e jovens envolvidos com o cometimento de atos infracionais inseridos em instituições de internação no Brasil, notadamente, foi privada de um processo de socialização saudável, do acesso às políticas públicas como educação, esporte, lazer, saúde, profissionalização e convivência familiar e comunitária, fatores estes fundamentais para a formação do indivíduo enquanto cidadão. Cordeiro e Volpi (2010) em um estudo realizado para caracterizar a população privada de liberdade no Brasil na década de 1990 demonstram que estão presentes nas condições de vida diferentes expressões de vulnerabilidade falta de acesso à infraestrutura de saneamento básico, desemprego, trabalho infantojuvenil, baixa escolarização, uso de drogas, insuficiência de renda, pobreza etc.

Conforme aponta Sales (2007, p. 83), “A reprodução social dos indivíduos em face de tantos dados que falam de vidas ameaçadas e de sofrimento real, portanto, não deve ser vista como algo estritamente privado, mas sim como uma pauta central da esfera pública"

O envolvimento de adolescentes e jovens em situações de violência está permeado por um contexto mais amplo de determinações, que extrapola a responsabilização do sujeito em relação aos seus deveres frente aos padrões de sociabilidade vigentes. 
Oriundos de uma lógica perversa na qual as relações sociais estão submetidas a uma intervenção estatal, que historicamente tem ignorado as determinações estruturais e as diferentes condições sociais e econômicas a que estão sujeitas os indivíduos na sociedade, adolescentes e jovens expostos a fatores de vulnerabilidade e risco à violência tornam-se alvos privilegiados das ações de repressão estatal, bem como de ações de grupos criminosos. Cordeiro e Volpi (2010) afirmam que "Aqueles mais afetados pelo desemprego e marginalização do sistema educacional são os que sofrem maior risco de serem vítimas da violência arbitrária da polícia, bem como da criminalidade comum".

Diante disso, a população mais empobrecida acaba sofrendo muito mais diante da faceta repressora do Estado. Exposta a situações de insegurança, medo, risco e violência, acaba por viver sob uma sensação contínua de desproteção.

Neste sentido, adolescentes e jovens oriundos das camadas da população mais empobrecidas igualmente sofrem com os dilemas inerentes a uma vida de privações econômicas, sociais e culturais, estando mais expostos à situações de violência e consequentemente a uma atuação estatal mais incisiva do ponto de vista repressivo. Conforme aponta Fraga e Iulianelli (2003, p. 10), em seu livro Jovem em tempo real, "A maioria dos direitos econômicos, sociais e culturais é negada a este segmento da população. A educação formal não se mostra adequada à atual conjuntura da juventude $e$ são negados o acesso ao trabalho e aos meios legais de geração de emprego e renda".

Neste processo de precarização humana e social, a incorporação das convenções sociais e dos parâmetros legais de sociabilidade resta-se muito prejudicada durante o processo de desenvolvimento pessoal e social dos adolescentes e jovens mais expostos às situações de violência em seu cotidiano. Aqueles que, inseridos em um contexto de privações materais, encontram bem mais dificuldades no processo de educação para o restabelecimento de uma vida em liberdade de acordo com os padrões oficiais de sociabilidade. Estes não gozam de mínimas condições de acesso a bens e serviços públicos capazes de contribuir com o processo de desenvolvimento pessoal e social mediante aos desafios impostos pela natureza das relações sociais na sociedade capitalista.

Excluídos socialmente e ainda expostos a um contexto de violência, adolescentes e jovens de camadas mais empobrecidas tornam-se alvos frágeis e mais suceptíveis às 
diversas formas de exploração inscritas no âmbito das relações desse contexto. As práticas infracionais passam a fazer parte de um conjunto de práticas engendradas na trama de relações determinadas por uma sociabilidade de natureza violenta.

Considerados por uma parcela significativa da sociedade como "bandidos" e tratados pelo Estado brasileiro como "menores infratores", adolescentes e jovens autores de atos infracionais, quando privados de liberdade em unidades de internação no Brasil, receberam historicamente um atendimento institucional que passou alhures de um tratamento considerado humanamente aceitável, questão esta que em determinados aspectos sobrevive até a atualidade.

Durante toda a vigência do Código de Menores, de 1927 até a promulgação do Estatuto da Criança e do Adolescente - ECA (Lei 8.069, 1990), as crianças e adolescentes pobres foram tratados como menores delinquentes, metáforas da violência (SALES, 2007). A institucionalização de crianças e adolescentes pobres no Brasil foi uma prática corrente e tratada por décadas no país como uma resposta aceitável socialmente e uma alternativa politicamente instituída mediante os problemas relacionados à infância e à juventude, levando à criminalização de situações sociais vividas por crianças, adolescentes e jovens.

Embora com o ECA as crianças e adolescentes passaram a ser considerados sujeitos de direitos, no que tange ao tratamento aos adolescentes em conflito com a lei, a realidade das instituições de internação no Brasil historicamente revelam uma insuficiência de condições para a garantia dos direitos assegurados legalmente aos mesmos e persistindo uma desconsideração às garantias legais enunciadas na lei $8.069 / 90$.

Em 2003 o Instituto de Pesquisa Econômica Aplicada (IPEA) realizou uma pesquisa sobre a realidade das unidades de internação no Brasil e verificou que, embora os adolescentes internados tenham assegurados direitos e garantias pelo Estatuto da Criança e do Adolescente, não possuem a garantia de que estando em internação terão seus direitos efetivados.

[...] muitos desses adolescentes convivem cotidianamente não apenas com o não-cumprimento das determinações específicas para a medida de internação que, em si, significa a privação temporária do direito de ir e vir, não mais que isso -, mas com a violação de seus direitos como adolescentes, previstos no 
ECA, e dos direitos como seres humanos, previstos em documentos internacionais dos quais o Brasil é signatário (SILVA; GUERESI, 2003, p. 10).

Inseridos em uma ordem sociocultural, política e jurídica, cujos valores legitimados socialmente são expressão dos interesses dos grupos hegemônicos e alijados dos direitos a eles garantidos legalmente, adolescentes e jovens em situação de vulnerabilidade social constituem-se parte significativa da parcela da população juvenil envolvida no cometimento de atos infracionais no Brasil, sendo estes a maioria dos adolescentes em cumprimento de medidas socioeducativas nas unidades de internação no país, o que demonstra a complexa trama de relações estabelecidas entre a situação econômica e social do Brasil e a forma como o Estado brasileiro tem correspondido a esta realidade, no que tange à atuação frente ao fenômeno da violência e a sua relação com a juventude e o cometimento de atos infracionais.

\section{A política pública de socioeducação e a privação de liberdade de adolescentes e jovens no Brasil}

Como garantidor da regulação das condições para a reprodução da vida social, o Estado exerce ao mesmo tempo uma função protetora e uma função repressora. 0 atendimento das necessidades dos cidadãos e a repressão de situações que estejam em desacordo com o pacto socialmente construído e juricamente estabelecido é uma atribuição delegada pela sociedade ao Estado, por meio do pacto societário. Cabe ao Estado, proporcionar formas de controle, equalização, integração e/ou promoção social a todos os seus cidadãos.

Conforme vimos, diante das diferentes expressões da violência, dentre elas as que envolvem a juventude e o cometimento de atos infracionais, o Estado tem o dever de buscar diferentes formas de enfrentamento, seja pela vida protetiva e ou pela via repressiva.

A atenção à juventude brasileira é um papel importante a ser desempenhado pelo Estado frente à necessidade de manutenção dos padrões de sociabilidade de acordo com o estabelecido pelo pacto social.

Pensar na formação pessoal, educacional e profissional dos jovens torna-se um desafio ao se planejar ações de crescimento econômico, encremento tecnológico e 
demais ações necessárias para o desenvolvimento de um país, pois as condições para a manutenção da mão de obra para o mercado de trabalho capitalista perpassam as questões da promoção social e profissional da juventude. Doravante, a formação de uma cultura cívica, o fortalecimento de convenções sociais em favor de relações sociais mais justas e solidárias entre os cidadãos perpassa também as questões da juventude, uma vez que é nesta fase da vida que se forma a identidade do sujeito, bem como os principais valores que norteiam sua vida no futuro.

As relações sociais, os pactos, os valores e ações inerentes à vida cotidiana em liberdade perpassa um projeto de sociedade, uma ética humana e social, uma construção dialética do bem viver, como já anunciada por Aristóteles em A política. De acordo com Morais e Pescarolo (2008, p. 2), “[...] a formação dos jovens depende da capacidade da sociedade na qual ele vive de orientá-lo para o que é entendido como seus valores, sejam eles positivos ou negativos. Para tanto, são necessárias instituições e figuras apropriadas para este fim". A educação voltada para a juventude, por sua vez, deve garantir meios para o aprendizado desta parcela da população a uma convivência social democrática. Conforme dispõe Sales (2007) a juventude é o termômetro da democracia.

Assim, podemos dizer que na contemporaneidade a juventude em conflito com a lei se materializa como uma das questões sociais mais expressivas e desafiadoras à sociedade, pois o que está em jogo é o padrão de sociabilidade vigente.

Instituições de controle social, como a família, a escola, a igreja, a imprensa etc., são responsáveis, pela formação sociocultural e moral dos indivíduos de acordo com os valores, regras e normas e demais elementos próprios da vida civil; e as instituições de repressão estatal, como a polícia e as prisões, são responsáveis por coibir toda e qualquer ação que seja considerada exceção ${ }^{1}$ à regra nas relações sociais.

A partir da vigência do Estatuto da Criança e do Adolescente (1990), o Estado brasileiro, mediante poder judiciário, passou a aplicar medidas socioeducativas aos adolescentes em conflito com a lei. Medidas estas, de meio aberto, quando executadas por instituições e ou programas junto de adolescentes ainda em liberdade; e restritivas e

\footnotetext{
${ }^{1}$ Exceção "é aquilo que não se pode reportar; ela subtrai-se à hipótese geral, mas ao mesmo tempo torna evidente com absoluta pureza um elemento formal especificamente jurídico: a decisão. Na sua forma absoluta, o caso de exceção se verifica somente quando se deve criar a situação na qual possam ter eficácia normas jurídicas" (SCHMITT, 1992, apud AGAMBEN, 2004, p. 39).
} 
ou privativas de liberdade, quando executadas junto dos adolescentes quando estes passam a estar sob a tutela estatal em instituições de semiliberdade e ou de internação, respectivamente.

O Estatuto da Criança e do Adolescente - ECA (Lei 8.069/90) foi um marco nacional para o desenvolvimento das políticas de atenção à infância e adolescência. A socioeducação construiu, portanto, o lastro de sua sustentação, enquanto política pública, com base nos princípios, concepções e objetivos dispostos no ECA.

A partir da doutrina da proteção integral tanto a criança quanto o adolescente passaram a ser considerados sujeitos em condição peculiar de desenvolvimento, prioridade absoluta no que dispõe a legislação. Esta legislação se inscreve em um contexto em que a sociedade brasileira vivenciava um momento histórico de avanços sociais e políticos, após a Constituição de 1988. Sua repercussão impactou no aprimoramento das políticas de atenção à crianças e adolescentes.

Além das bases legais nacionais, a política pública de socioeducação se assenta nas legislações internacionais, ${ }^{2}$ as quais o Brasil é signatário. Buscou-se, diante destas e em consonância com suas próprias legislações (Constituição Federal de 1988 e Estatuto da Criança e do Adolescente de 1990), desenvolver os princípios, concepções e objetivos para a política pública de atendimento aos adolescentes e jovens autores de atos infracionais. No âmbito deste processo, a sociedade civil e o Estado tiveram por conquista a construção do Sistema Nacional de Atendimento Socioeducativo (SINASE), que define os princípios, conceitos e objetivos da socioeducação enquanto política pública, que, recentemente, no dia 18 de janeiro de 2012 vigorou como lei no Brasil, sob o número $12.594 / 2012$.

O SINASE foi apresentado pela Secretaria Especial dos Direitos Humanos da Presidência da República e pelo Conselho Nacional dos Direitos da Criança e do Adolescente, como fruto de uma "[...] construção coletiva que envolveu nos últimos anos diversas áreas de governo, representantes de entidades e especialistas na área, além de

\footnotetext{
2 Declaração Universal dos Direitos Humanos (1948), Declaração Universal dos Direitos da Criança e do Adolescente (1959), Convenção Internacional dos Direitos da Criança e do Adolescente (1989), Sistema Global e Sistema Interamericano dos Direitos Humanos: regras de Beijing, regras mínimas das Nações Unidas para a Proteção dos Jovens Privados de Liberdade).
} 
uma série de debates protagonizados por operadores do Sistema de Garantia de Direitos em encontros regionais que cobriram todo o País" (BRASIL, 2006, p. 13).

Verifica-se que a socioeducação é uma política pública que resultou de um processo no qual o Estado e a sociedade civil buscaram meios para a promoção pessoal, social, educacional, cultural e política de adolescentes autores de atos infracionais, que estando em conflito com a lei, foram determinados pelo poder judiciário a cumprir uma medida socioeducativa, conforme dispõe o ECA. ${ }^{3}$

São várias as medidas socioeducativas previstas pelo ECA que são impostas aos adolescentes autores de atos infracionais. ${ }^{4}$ Cabe ressaltar que todas as medidas socioeducativas estão subordinadas aos princípios da brevidade e excepcionalidade e ainda à consideração da condição peculiar de desenvolvimento do adolescente. A execução das medidas socioeducativas está subordinada no Brasil às disposições da Lei 8.069/90 e da lei 12.594/2012, além das disposições das legislações internacionais conforme descritas anteriormente.

A política de socioeducação é, portanto, responsável por proporcionar o atendimento socioeducativo aos adolescentes e jovens em conflito com a lei. Durante o processo socioeducativo, busca-se desenvolver ações de promoção pessoal e social, trabalho de orientação, educação formal, atividades pedagógicas, de lazer, esportivas, de profissionalização, bem como demais questões inerentes ao desenvolvimento do sujeito frente aos desafios da vida em liberdade.

\footnotetext{
${ }^{3}$ As medidas socioeducativas previstas pela Lei 8.069/90 são as seguintes, conforme dispõe seu artigo 112, citado a seguir. Verificada a prática de ato infracional, a autoridade competente poderá aplicar ao adolescente as seguintes medidas:

I - advertência;

II - obrigação de reparar o dano;

III - prestação de serviços à comunidade;

IV - liberdade assistida;

$V$ - inserção em regime de semi-liberdade;

VI - internação em estabelecimento educacional;

VII - qualquer uma das previstas no art. 101, I a VI.

$\S 1$ ㅇ A medida aplicada ao adolescente levará em conta a sua capacidade de cumpri-la, as circunstâncias e a gravidade da infração.

$\S 2$ 2 Em hipótese alguma e sob pretexto algum, será admitida a prestação de trabalho forçado.

$\S$ зㅇ Os adolescentes portadores de doença ou deficiência mental receberão tratamento individual e especializado, em local adequado às suas condições (BRASIL, 1990).

${ }^{4}$ Cabe informar que os atos infracionais são condutas equiparadas às tipificações do Código Penal Brasileiro, no que se refere às condutas consideradas crime.
} 
A busca do rompimento com os ciclos de violência vivenciados historicamente pelos adolescentes e jovens e a construção de meios para educação destes para a vida em liberdade, a partir de um padrão de sociabilidade ético e saudável, é, portanto, o desafio da política de socioeducação.

Os princípios que regem a política pública de socioeducação, conforme dispostos no SINASE, buscam salvaguardar a garantia dos direitos dos adolescentes, já assegurados pelo conjunto de leis inerente ao sistema proteção social da infância e da juventude no país. Estes abrangem os níveis dos direitos individuais do adolescente, da gestão da política, de seu financiamento, bem como das questões do controle social e a mobilização da opinião pública frente à referida política.

Visando a garantia da efetivação do processo socioeducativo, o Estado deve executar a política pública de socioeducação atendendo aos seguintes parâmetros, divididos nos referidos eixos temáticos: suporte institucional e pedagógico; diversidade étnico-racial, de gênero e de orientação sexual; cultura, esporte e lazer; saúde; profissionalização/trabalho/previdência; família e comunidade e segurança.

Tais parâmetros se inscrevem num contexto complexo e multidimensional inerente aos processos de inclusão e acessibilidade dos adolescentes ao sistema de garantia de direitos, bem como aos bens e serviços socialmente construídos e disponibilizados pelo Estado por meio das políticas públicas. Para que os adolescentes e jovens em cumprimento de medidas socioeducativas possam conquistar novamente o direito de viver em liberdade é necessário que todos os referidos parâmetros sejam estruturados, dando sustentação às ações a serem executadas pela política pública de socioeducação.

Partindo dos princípios, parâmetros e dimensões básicas de atendimento dispostas no SINASE a socioeducação se constitui uma política pública de jurídico-sancionatória e sociopedagógica, ressaltando-se que esta última dimensão deve se sobrepor à primeira.

Durante o processo socioeducativo, o adolescente deve receber atendimento multidisciplinar, dando-se ênfase à sua escolarização, profissionalização e estímulo à convivência familiar e comunitária. As medidas de restrição e privação de liberdade deverão ser aplicadas apenas quando houver grande reincidência de atos infracionais ou ainda em virtude da gravidade do ato infracional praticado. Durante o processo socioeducativo 
O adolescente deve ser alvo de um conjunto de ações socioeducativas que contribua na sua formação, de modo que venha a ser um cidadão autônomo e solidário, capaz de se relacionar melhor consigo mesmo, com os outros e com tudo que integra a sua circunstância e sem reincidir na prática de atos infracionais. Ele deve desenvolver a capacidade de tomar decisões fundamentadas, com critérios para avaliar situações relacionadas ao interesse próprio e ao bem-comum, aprendendo com a experiência acumulada individual e social, potencializando sua competência pessoal, relacional, cognitiva e produtiva (BRASIL, 2006, p.46).

Desta forma, a socioeducação tem um papel fundamental. O de atuar como espaço de mediação entre os adolescentes e jovens e a sociedade, de forma a contribuir efetivamente para o seu retorno ao convívio familiar, comunitário e social, auxiliando-os a usufruir de sua liberdade, sem o cometimento de novos atos infracionais. Ou seja, o papel da socioeducação, constitui-se em encontrar meios para educar adolescentes e jovens para a vida em liberdade.

O rompimento com o ciclo vicioso das práticas infracionais, no qual o adolescente se encontrara inserido antes de iniciar o processo socioeducativo, e a promoção de novos meios de socialização pelos quais o adolescente tenha condições de pautar-se em valores éticos e morais aceitáveis para o conjunto da sociedade, constitui-se o principal objetivo da socioeducação.

A formação conjunta de um novo projeto de vida para o adolescente, construído sob a orientação dos profissionais da socioeducação e a consequente retaguarda do sistema de garantia de direitos, por meio da disponibilização de bens e serviços ao mesmo, são as condições necessárias para que o adolescente possa traçar suas metas e objetivos futuros e encontrar meios para efetivá-los distante do ciclo da violência.

\begin{abstract}
A socioeducação como práxis pedagógica propõe objetivos e critérios metodológicos próprios de um trabalho social reflexivo, crítico e construtivo, mediante processos educativos orientados à transformação das circunstâncias que limitam a integração social, a uma condição diferenciada de relações interpessoais, e, por extensão, à aspiração por uma qualidade de convívio social (PARANÁ, 2006b, p. 19).
\end{abstract}

As práticas de socioeducação se efetivam por meio de espaços de interlocução entre os educadores, adolescentes e jovens e a sociedade em geral. Os adolescentes e jovens devem ser sujeitos ativos do processo socioeducativo, acompanhando a dinâmica 
do atendimento de forma autônoma a fim de contribuir com os avanços necessários ao fortalecimento da desta política pública enquanto uma política educacional, espaço legítimo de convivência juvenil e de educação para a liberdade.

Neste contexto, para Costa (2001, apud PARANÁ, 2006b, p. 46) “[...] o papel do educador é o de criar espaços, organizar meios e produzir acontecimentos que façam a educação acontecer. Assim, os educandos se tornam parceiros, interlocutores ativos e críticos dos agentes responsáveis pelo processo de socialização".

A socioeducação visa construir junto dos adolescentes e jovens novos e apropriados conceitos de vida, pela reflexão sobre valores, o fortalecimento dos princípios éticos da vida social e ainda o acesso destes aos bens e serviços socialmente construídos, de tal forma que os adolescentes e jovens privados de liberdade possam retornar ao convívio em sociedade, ressignificando o lugar que ocupam na sociedade enquanto sujeitos livres e cidadãos autônomos no âmbito das esferas social, cultural e política.

Disso posto, tal compromisso se traduz em ações que se complementam no movimento do processo socioeducativo junto dos adolescentes. O papel do Estado e da sociedade civil constitui-se pela busca da efetivação desta política educacional frente à polêmica questão dos adolescentes e jovens em conflito com a lei e de sua relação com o fenômeno da violência. Tanto o Estado como a sociedade civil, devem trabalhar pela construção e aprimoramento desta política pública, sob a lógica de uma proposta de educação para adolescentes e jovens que seja capaz de promover meios para a vida em liberdade, que não se limite a uma visão individualista e focada no indivíduo, mas que busque enfrentar as questões de ordem estrutural que impedem que os adolescentes em conflito com a lei obtenham as condições adequadas para seu desenvolvimento, enquanto sujeitos em liberdade no âmbito da sociedade. Conforme aponta Gramsci (2001, v. 1, p. 406), "Possibilidade quer dizer 'liberdade'." Partindo deste conceito de liberdade, na sua interface com a política de socioeducação, verifica-se que o desafio posto para essa política supera o simples retorno e ou orientação do adolescente para a vida em liberdade, pois implica oferecer aos adolescentes e jovens condições para que possam usufruir de sua liberdade enquanto sujeitos de direitos. Tais condições são construídas pelo conjunto de ações de natureza pedagógica e social a que os mesmos 
devem ser alvo de atenção durante o tempo em que cumprem a medida socioeducativa. As possibilidades de promoção pessoal e social no âmbito do processo socioeducativo são construídas pela equipe de profissionais da política de socioeducação e devem ser efetivadas em conjunto com a família, com os demais órgãos do Estado, em suas várias instâncias federativas, e com a sociedade em geral.

A política pública de socioeducação possui uma dimensão intersetorial. Está inserida nos meandros dos diferentes subsistemas do sistema de proteção social, uma vez que para sua execução é necessária uma gestão compartilhada com as demais políticas públicas, em especial com as políticas de saúde, educação, trabalho, assistência social e segurança pública, visto que se busca a construção de possibilidades para a preparação do adolescente e do jovem para a vida em liberdade, e que possibilidade quer dizer liberdade, conforme vimos em Gramsci (2001).

O Sistema Nacional de Atendimento Socioeducativo (SINASE) é um subsistema do sistema de garantia de direitos da criança e do adolescente, "[...] o qual se comunica e sofre interferência dos demais subsistemas internos ao Sistema de Garantia de Direitos (tais como Saúde, Educação, Assistência Social, Justiça e Segurança Pública)" (BRASIL, 2006, p. 22).

No âmbito do atendimento socioeducativo, considerando o disposto no SINASE, busca-se no aporte legal as garantias jurídicas, políticas e sociais dos adolescentes e, na interface com os serviços públicos e os demais atores sociais presentes na sociedade civil, a inclusão destes na sociedade.

\footnotetext{
O SINASE é o conjunto ordenado de princípios, regras e critérios, de caráter jurídico, político, pedagógico, financeiro e administrativo, que envolve desde o processo de apuração de ato infracional até a execução de medida socioeducativa. Esse sistema nacional inclui os sistemas estaduais, distrital e municipais, bem como todas as políticas, planos, e programas específicos de atenção a esse público (BRASIL, 2006, p. 22).
}

Neste subsistema se mobilizam outros subsistemas de atendimento. $\mathrm{O}$ adolescente é para todos eles o foco de atenção durante seu processo socioeducativo, uma vez que deve ter garantido todos os seus direitos, visando seu desenvolvimento pessoal e social. A não violação dos direitos dos adolescentes torna-se fator primordial no processo de reinserção destes no âmbito das relações sociais, bem como ao desenvolvimento de 
condições pessoais e sociais para a não reiteração do cometimento de novos atos infracionais.

Inscrita neste contexto, a política de socioeducação, em especial para adolescentes e jovens em regime de privação de liberdade, configura-se como um terreno arenoso frente à sua interlocução com os diferentes atores sociais. $\mathrm{O}$ atendimento socioeducativo demanda do Estado o oferecimento de condições apropriadas ao atendimento integral dos adolescentes. Durante o cumprimento da medida socioeducativa de internação, os esforços devem ser conjugados pelas diferentes políticas públicas: educação, esporte, lazer, segurança pública, assistência social, cultura, saúde, entre outras.

Segundo o Sistema Nacional de Atendimento Socioeducativo, as diretrizes pedagógicas da política de socioeducação são as seguintes:

1. Prevalência da ação socioeducativa sobre os aspectos meramente sancionatórios; [...]

2. Projeto pedagógico como ordenador de ação e gestão do atendimento socioeducativo; [...]

3. Participação dos adolescentes na construção, no monitoramento e na avaliação das ações socioeducativas; [...]

4. Respeito à singularidade do adolescente, presença educativa e exemplaridade como condições necessárias na ação socioeducativa; [...]

5. Exigência e compreensão, enquanto elementos primordiais de reconhecimento e respeito ao adolescente durante 0 atendimento socioeducativo; [...]

6. Diretividade no processo socioeducativo; [...]

7. Disciplina como meio para a realização da ação socioeducativa; [...]

8. Dinâmica institucional garantindo a horizontalidade na socialização das informações e dos saberes em equipe multiprofissional; [...]

9. Organização espacial e funcional das Unidades de atendimento socioeducativo que garantam possibilidades de desenvolvimento pessoal e social para o adolescente; [...]

10. Diversidade étnico-racial, de gênero e de orientação sexual norteadora da prática pedagógica; [...]

11. Família e comunidade participando ativamente da experiência socioeducativa; [...]

12. Formação continuada dos atores sociais. [...] (BRASIL, 2006, p. 47-49).

Sendo assim, a política de socioeducação se inscreve na contemporaneidade, como uma nova política educacional, inserida em um contexto de violações de direitos, da banalização da violência, de insuficiência e/ou ausência de meios para a promoção social do adolescente, da carência de estímulos a uma convivência social regulada pelo código de valores morais e éticos socialmente aceitáveis, que regem as relações sociais no 
âmbito de um Estado Democrático de Direito. Neste contexto, "[...] a formação dos jovens seria responsabilidade de toda a sociedade. De forma mais precisa do conjunto de instituições que compõe a sociedade: família, escola, trabalho, etc." (MORAIS; PESCAROLLO, 2008, p. 1, grifo do autor).

Assim, empreender ações para a materialidade da proposta socioeducativa, constitui-se um desafio para a sociedade contemporânea, frente ao objetivo de realizar a mediação dos adolescentes e jovens em cumprimento de medida socioeducativa junto à sociedade, uma vez que esta política tem por objetivo educá-los para a vida em liberdade.

\section{A socioeducação é uma política de educação para a vida em liberdade?}

Em um Estado Democrático de Direito, a liberdade não se constitui apenas um direito fundamental dos indivíduos, mas é compreendida como um amplo conceito que permeia tanto a sociedade civil, quanto o próprio Estado, sendo inerente ao projeto democrático.

Sánchez Vázquez (2001, p. 69) afirma que a "[...] verdadeira democracia aparece assim vinculada necessariamente à liberdade", e ainda revisitando "Os cadernos do Cárcere" de Antonio Gramsci (2001, v. 1, p. 406), no qual o autor afirma que “Possibilidade quer dizer 'liberdade'. A medida das liberdades entra no conceito de homem. [...] Mas a existência das condições objetivas - ou possibilidade, ou liberdade ainda não é suficiente: é necessário 'conhecê-las' e saber utilizá-las. Querer utilizá-las".

Assim, a concepção de liberdade em Gramsci "[...] tem a conotação positiva de expansão social, não de cerceamento e limitação: a liberdade individual não termina onde começa a dos outros, mas se desenvolve ainda mais quando se encontra com a dos outros" (SEMERARO, 1999, p. 161).

Tomando por base a concepção gramsciana de liberdade é que buscamos discutir a política pública de socioeducação, enquanto uma política de educação de adolescentes e jovens em conflito com a lei para a vida em liberdade. Conforme dispõe o Sistema Nacional de Atendimento Socioeducativo (BRASIL, 2006, p.46):

O adolescente deve ser alvo de um conjunto de ações socioeducativas que contribua na sua formação, de modo que venha a ser um cidadão autônomo e solidário, capaz de se relacionar melhor consigo mesmo, com os outros e com 
tudo que integra a sua circunstância e sem reincidir na prática de atos infracionais. Ele deve desenvolver a capacidade de tomar decisões fundamentadas, com critérios para avaliar situações relacionadas ao interesse próprio e ao bem-comum, aprendendo com a experiência acumulada individual e social, potencializando sua competência pessoal, relacional, cognitiva e produtiva.

Assim, em uma sociedade democrática, pensar a socioeducação enquanto uma proposta de educação para a vida em liberdade impõe ao Estado e à sociedade civil, não somente, o desafio de trabalhar com a formação do sujeito - adolescente, a fim de prepará-lo como cidadão para a vida em liberdade, mas também o desafio de extrapolar o campo da formação subjetiva, acessando outras esferas da sociedade, uma vez que a liberdade constitui-se ontologicamente no seio da construção da vida em coletividade e possui uma natureza eminentemente material e política.

A ausência de possibilidades para a consolidação de uma vida ativa e participativa na esfera pública tem sido característica imperativa na vida da maioria dos adolescentes e jovens em conflito com a lei no Brasil.

Podemos dizer que muitos adolescentes em conflito com a lei, que estão privados de liberdade no país, já estavam privados deste direito antes mesmo de suas apreensões. O cárcere torna-se apenas mais uma fatalidade inerente à vida de privações a que são submetidos ao longo da vida. As privações vividas não se resumem a privações de cunho socioeconômico, mas a privações de afeto, de vínculos familiares e comunitários, de educação, de saúde, de esporte, de lazer, de expectativas de vida e de futuro, ou seja, de possibilidades de liberdade. Segundo Jaguaribe (2006, p. 11) ou "[...] o Brasil supera a marginalidade e a incorpora à cidadania, ou a marginalidade asfixiará o país num prazo não muito grande".

O adolescente, que invisível como sujeito de direitos, já privado de possibilidades de liberdade, uma vez em conflito com a lei, torna-se visível como "infrator", "delinquente", "bandido", conquistando assim sua visibilidade perante a família, a sociedade e o Estado. Torna-se, com isso, alvo da repressão estatal, "[...] expressão do clamor punitivo que grassa na sociedade brasileira por maior repressão, mais prisões e penas mais rigorosas" (SALES, 2007, p. 65).

O mesmo Estado que não the garantiu condições para a proteção à vida em liberdade, reprime o adolescente, responsabilizando-o por estar em conflito com a lei, 
privando-o do direito à liberdade sob o argumento de socioeducá-lo para o retorno ao convívio social. "O severo controle penal e exterminador dos pobres e outros marginalizados [...]" se expressa cotidianamente no trato com adolescentes em conflito com a lei (SALES, 2007, p. 65).

Cabe ressaltar que, se o adolescente convive em um contexto de privações, de violações de direitos e de ausência de garantias, torna-se difícil incorporar ao longo de seu desenvolvimento a disciplina imposta pelas regras e normas inerentes ao contrato social.

Conforme aponta Dayrell (2007), a juventude é uma "construção histórica e social" [...], entretanto, sabe-se que o jovem constrói-se enquanto sujeito, baseado nas experiências do seu cotidiano. De tal forma, a socioeducação figura-se como uma política de educação para a vida em liberdade, na medida em que efetiva ao longo do processo socioeducativo os encaminhamentos necessários à incorporação dos adolescentes e jovens à sociedade. Esse processo se efetiva mediante o acesso aos bens e serviços públicos e aos direitos do sujeito, no âmbito de um Estado e na sua relação com a família, com a comunidade e com a sociedade civil em geral, respeitando-se o seu perfil pessoal, sua cultura, sua condição de saúde, suas relações afetivas, sua escolarização, entre outros aspectos de sua vida cotidiana.

Em uma sociedade, em que o status de cidadania não foi uma conquista universal, mas apenas um privilégio dos setores que foram sendo beneficiados pelo crescimento econômico e pela industrialização (SINGER, 2003), o contrato social se vulnerabiliza, de modo que o convívio social é particularmente afetado. Neste processo, a juventude é a parcela da sociedade que mais sofre as consequências da fragilidade da ordem democrática, necessitando de atenção especial por parte do Estado e da sociedade, frente à sua condição peculiar de desenvolvimento, conforme prevê o Estatuto da Criança e do Adolescente, Lei 8.069/90.

Disso posto, a socioeducação, enquanto proposta de educação para a vida em liberdade propõe-se a preparar os adolescentes para o convívio social, despontando-se no cenário contemporâneo como uma política pública na qual se incorporam os desafios inerentes a uma sociabilidade humana fundada em valores democráticos.

Assim, educar adolescentes em conflito com a lei para uma vida econômica, social, cultural e políticamente autônoma, inscrita em um contexto democrático, no qual o status 
de cidadania é devido a todos e no qual "possibilidade, quer dizer "liberdade'" (GRAMSCl, 2001) é um desafio da humanidade em seu estágio atual, que se depara com uma juventude, que, nas palavras de Dayrell (2007), não se encontra consenso para defini-la. Entretanto, sabe-se que o jovem constrói-se enquanto sujeito, baseado nas experiências do seu cotidiano.

Portanto, torna-se explícito, neste debate sobre a socioeducação enquanto proposta de educação para a vida em liberdade, que a questão da juventude em conflito com a lei se inscreve no âmbito das relações sociais e é no âmbito destas relações que o processo socioeducativo encontra o substrato para a realização de suas práticas.

A melhoria das condições objetivas e materiais da vida dos sujeitos que compõem as partes do contrato social é, portanto, uma condição para o avanço da democracia e para a melhoria do convívio social entre os indivíduos no âmbito do Estado. À socioeducação, cabe uma fatia de responsabilidade neste complexo conjunto de relações e necessidades: a de educar adolescentes e jovens para a vida em liberdade em uma sociedade na qual a democracia não garante condições iguais a todos os sujeitos e na qual a concepção de liberdade hegemônica ainda é uma concepção centrada na responsabilização do indivíduo em favor da preservação da histórica divisão de classes.

\section{Considerações finais}

Entendemos que a política de socioeducação se inscreve no contexto contemporâneo como uma tentativa de resposta por parte do Estado e da sociedade civil frente às questões que envolvem o binômio juventude/violência, a fim de superar junto dos adolescentes em conflito com a lei os desafios impostos por uma socialização historicamente construída sob as determinações de uma sociedade que se constituiu historicamente à luz de princípios capitalistas burgueses, que sustentou condições históricas que determinaram a formação de uma sociedade desigual social e economicamente.

Verificamos que o processo socioeducativo, enquanto parte da vida dos adolescentes durante um período específico, pode se constituir como um momento de educação para a vida em liberdade na medida em que se busque a construção de meios para uma vida humana, mais digna e por consequência mais aberta à incorporação de 
valores éticos e morais mais apropriados às práticas sociais e ao aprendizado para a vida em liberdade.

Consideramos, conforme o exposto, que educar para a vida em liberdade, implica bem mais que ações repressoras por parte do Estado e da sociedade, implica um conjunto de práticas que, inseridas no âmbito do processo sociocultural e político do adolescente e do jovem, podem contribuir para seu processo de desenvolvimento pessoal e social, elevando sua consciência para uma dimensão sociopolítica, enquanto cidadão no âmbito do Estado Democrático de Direito.

Assim, para construir uma política pública de socioeducação cujo desafio seja extrapolar continuamente o ambiente de privação de liberdade e trabalhar na perspectiva das relações sociais é o desafio de uma política pública que se caracteriza como uma política que visa educar para a vida em liberdade.

A preparação do adolescente para a vida em sociedade e o fomento do debate sobre a juventude junto à sociedade compõem os desafios inerentes à política de socioeducação para a construção dos melhores meios para o desenvolvimento dos adolescentes e jovens no âmbito do convívio social na contemporaneidade.

\section{Referências}

AGAMBEM, G. Homo sacer: o poder soberano e a vida nua. Belo Horizonte: UFMG, 2004.

ARISTÓTELES. A política. Rio de Janeiro: Edições de Ouro, 1965.

FRAGA, P. C. P. Política, isolamento e solidão: práticas sociais na produção da violência contra jovens. In: SALES, M. A. Política Social, Família e Juventude: uma questão de direitos. 6ạ ed. São Paulo: Cortez, 2010.

BRASIL. Secretaria Especial dos Direitos Humanos. Conselho Nacional dos Direitos da Criança e do Adolescente. Sistema Nacional de Atendimento Socioeducativo. Brasília: CONANDA, 2006.

BRASIL, Presidência da República. Estatuto da Criança e do Adolescente. Lei 8.069/90. Dispõe sobre o Estatuto da Criança e do Adolescente e dá outras providências. Brasília, 13 jul. 1990. Disponível em: http://www.planalto.gov.br/ccivil 03/leis/L8069.htm. Acesso em: 18 de jan. 2011.

CORDEIRO, C. M. C.; VOLPI, M. Pesquisa quantitativa sobre adolescentes privados de liberdade no Brasil. In: VOLPI, M. O adolescente e o ato infracional. 8. ed. São Paulo: Cortez, 2010. p. 45-65. 
DAYRELL, J. O jovem como sujeito social. In: FÁVERO, O. et al. Juventude e contemporaneidade. Brasília: UNESCO, 2007.

FRAGA, P. C. P.; IULIANELLI, J. A. S. Jovens em tempo real. Rio de Janeiro: Editora DP\&A, 2003.

GRAMSCI, A. Cadernos do cárcere. 2. ed. Rio de Janeiro: Civilização Brasileira, 2001. v. 1.

JAGUARIBE, E. Atual problema do desenvolvimento brasileiro. Revista brasileira de ciências sociais, Belo Horizonte, v. 21, n. 60, fev. 2006.

MORAIS, P. R. B.; PESCAROLO, J. K. Quem tem medo dos jovens? 2008. Disponível em: <http://www.naoviolencia.org.br/pdf/quemtemedodosjovens.pdf>. Acesso em: 17 jan. 2011.

NOGUEIRA, M. A. Em defesa da política. São Paulo: SENAC, 2001.

PARANÁ. Governo do Paraná. Estatuto da Criança e do Adolescente, n. 8.069/90. Dispõe sobre o Estatuto da Criança e do Adolescente, e dá outras providências. Curitiba, 2006a. Instituto de Ação Social do Paraná. Cadernos do lasp. 2006b.

SALES, M. A. (in)visibilidade perversa: adolescentes infratores como metáfora da violência. São Paulo: Cortez, 2007.

SÁNCHEZ VÁZQUEZ, A. Entre a realidade e a utopia: ensaios sobre política, moral e socialismo. Rio de Janeiro: Civilização Brasileira, 2001.

SEMERARO, G. Gramsci e a sociedade civil: cultura e educação para a democracia. 2. ed. Petrópolis: Vozes, 1999.

SILVA, E. R. A.; GUERESI, S. Adolescentes em conflito com a lei: situação do atendimento institucional no Brasil. IPEA, Texto para discussão n. 979, 2003. Disponível em: <http://www.ipea.gov.br/pub/td/2003/td_0979.pdf>. Acesso em: 10 jan. 2012.

SINGER, P. Cidadania para todos. In: PINSKY, J.; PINSKY, C. B. (Org.). História da cidadania. São Paulo: Contexto, 2003.

WEBER, M. A política como vocação. In: . Ciência e Política: duas vocações. São Paulo: Martin e Claret, 2007. p. 59-124. 